\title{
Persistent Burnout Theory of Chronic Fatigue Syndrome
}

\author{
David Jameson \\ Independent Researcher, Ladysmith, Canada \\ Email: davidj@mind-body-health.net
}

Received 21 April 2016; accepted 4 June 2016; published 8 June 2016

Copyright (C) 2016 by author and Scientific Research Publishing Inc.

This work is licensed under the Creative Commons Attribution International License (CC BY). http://creativecommons.org/licenses/by/4.0/

(c) (i) Open Access

\begin{abstract}
There is no agreement on the etiology of chronic fatigue syndrome (CFS), and the main theories (behavioural and viral/immune) do not satisfactorily explain the condition. A growing body of evidence suggests that CFS may be caused by a dysfunction of the stress system-and the hypothalamic-pituitary-adrenal (HPA) axis in particular-as a result of chronic stress. CFS shares many similarities to occupational burnout, including similar symptoms, physiological abnormalities and triggers. After a brief review of the science of stress, burnout, central fatigue and CFS, I propose a model of CFS based on a state of persistent burnout that remains after the initial stressors have been removed. This persistence may be due to a combination of a dysregulation of the HPA axis, and behavioural factors. A novel treatment approach based on self-efficacy and positive goals is proposed.
\end{abstract}

\section{Keywords}

CFS, Burnout, Fatigue, HPA Axis

\section{Introduction}

Chronic Fatigue Syndrome (CFS) is the internationally accepted term for long-term, disabling fatigue along with other symptoms such as musculoskeletal pain, sleep disturbances and impaired concentration, which has no known medical cause. There is no objective test for the condition and it remains a diagnosis of exclusion [1]. Estimates of the prevalence of CFS range from $0.007 \%$ to $2.8 \%$ in the adult general population. CFS is frequently co-morbid with fibromyalgia, multiple chemical sensitivity, irritable bowel syndrome and temporomandibular joint disorder. Risk factors include older age, longer illness duration, fatigue severity, co-morbid psychiatric illness and a physical attribution for the illness [2].

There is no generally accepted theory for the etiology of CFS. The main contenders are the psychiatric (cognitive behavioral) theory and the viral theory. The cognitive behavioral theory posits that CFS is caused by an 
initial trigger (such as a virus or stressor), but maintained by behavioral factors such as de-conditioning, exercise avoidance and abnormal illness beliefs [3]. The viral theory posits that CFS is caused either by a so-far-undetected virus or that the immune system in patients is compromised and allows viruses such as herpes-virus to persist [4].

The problem with the cognitive behavioral theory is that it does not adequately explain all of the signs and symptoms of CFS, such as the endocrine and immune irregularities, simply putting these down to mind-body interactions without adequately explaining them. It also does not adequately explain findings about patients' history, personality and pre-morbid lifestyle [5]. A meta-analysis by Malouff et al. found that including cognitive elements in a treatment did not lead to a greater effect, and there appeared to be no empirical basis for including cognitive components in the treatment of CFS [6]. Exercise avoidance and de-conditioning do not adequately explain findings such as abnormal performance in repeated cardiopulmonary exercise tests [7] [8]. A review by Wiborg et al. found that the effectiveness of cognitive behavioral therapy (CBT) was independent of any persistent change in physical activity [9]. A case study by Friedberg found that improvement was associated with the substitution of stress-exacerbating activities with mood-enhancing, stress-reducing activities, rather than any increase in activity. This suggests that the patient's attitude towards the activity is more important than the actual amount of physical exertion [10].

Taken together, these findings suggest that de-conditioning, exercise avoidance and cognitive behavioral factors do not satisfactorily explain the etiology of CFS. The cognitive behavioral theory essentially explains CFS symptoms by saying "while your illness might have been triggered by a virus, it is being perpetuated by your beliefs", which does not really correspond with the experiences of the patients themselves. It is not surprising that there is such a vehement backlash against any psychological explanation for the illness [11].

The problem with the viral theory is that no single virus has been found in all CFS patients. While high titers of HHV6, EBV and other virus antibodies are commonly found in patients, this is also sometimes found in healthy patients and simply reflects prior infection. Furthermore, some research shows no immune dysfunction in patients at all [12]. It is also well established that stressors such as examinations can cause large increases in herpesvirus antibody titers [13]. It is possible that there is some as-yet-undiscovered virus hiding out in the bodies of CFS patients, but such a theory is not credible until evidence is produced.

\section{Hypothalamic-Pituitary-Adrenal Axis}

There are many different CFS symptoms - such as post-exertional malaise, anorexia, nausea, night sweats, dizziness, alcohol intolerance, autonomic dysfunction, immune system abnormalities and insomnia - and no two patients have exactly the same set of symptoms [2]. However, there are certain abnormalities that appear to be present in the majority of patients. One common finding is a dysfunction in the hypothalamic-pituitary-adrenal (HPA) axis, including blunted HPA axis responsiveness, mild hypocortisolism, and a lower than normal variation in the normal circadian pattern of HPA axis activation [14]. Given that the HPA axis is an important modulator of the immune system [15], this may explain the immune abnormalities seen in CFS.

Most CFS cases are triggered by either an infectious illness, a stressful life event, or a combination of the two [16]. Viral infections are physiologically stressful, and they activate the HPA axis in a similar way to psychological stressors [17].

A number of studies have shown that CFS patients tend to have a Th2-type immune response, and this has been shown to be due to increased sensitivity to cortisol. Increased sensitivity to cortisol is typically a result of long-term hypocortisolism, and is thought to be a compensatory mechanism [18].

CFS patients appear to have an "action-prone" (or hyperactive) personality [19], which then appears to result in a "crash" of the stress system due to excessive chronic stress [20]. The HPA axis dysfunction in CFS appears to be due to enhanced HPA axis negative feedback, which may be mediated by mineralocorticoid and glucocorticoid receptors in the brain [14]. Similar enhanced negative feedback is also seen in post-traumatic stress disorder (PTSD), burnout, childhood sexual abuse, adolescents exposed to earthquake-trauma, and chronic pelvic pain [21].

\section{Under-Activation of the HPA Axis}

While stress normally results in an increase in HPA axis activation, chronic long-term stress can paradoxically lead to an under-activation of the HPA axis, hypocortisolism, and fatigue [22]. This was first noted by Hans 
Selye, who termed it general adaptation syndrome (GAS). The earliest research showed that chronic stress was associated with a reduced daily output of cortisol. However this went against the prevailing dogma that stress was associated with high cortisol output, so the results languished for $10-15$ years. Subsequent research has shown that chronic stress can result in both high and low cortisol depending on the nature of the threat, the time since onset, and the person's response to the situation. Cortisol output tends to be elevated initially, and then tends to reduce as time passes [22]. Under-activation of the HPA axis is consistently seen in both PTSD and CFS [14] [22], as well as after the cessation of chronic stress [23].

\section{Cortisol Awakening Response}

The cortisol awakening response (CAR) is a measure of cortisol in the 30 - 60 minutes after waking, and is believed to be a reliable indicator of HPA axis responsiveness. Normally cortisol rises just after waking-similar to a mild stressor-in anticipation of events during the day [15]. During periods of stress, the CAR is elevated, whereas in CFS, chronic pain disorders, functional gastrointestinal disorders and PTSD, it tends to be blunted [24]. Two studies have shown that the hypocortisolism in CFS is normalised after treatment, and that response to treatment is associated with normalization of cortisol in patients [25] [26].

Hall et al. found that perceived stress management skills are related to greater CAR response in CFS patients, and a greater CAR results in reduced post-exertional malaise (PEM). The authors hypothesize that higher cortisol may protect against CFS symptoms such as PEM due to its effects on energy metabolism. Alternatively, the hypocortisolism in CFS and resulting changes in inflammatory cytokines may result in increased inflammation after exertion [27].

\section{Burnout}

Burnout is a state of emotional exhaustion, depersonalization, and reduced personal accomplishment, due to excessive demands of a job (e.g. workload or time pressure), and insufficient resources (e.g. being in control, or having a variety of tasks). It has been shown that job demands correlate with feelings of exhaustion in burned out workers [28].

Research has shown that patients suffering from fatigue, burnout, or exhaustion tend to have a reduced CAR compared to controls, whereas job stress and general life stress is associated with an increased CAR [29]. When comparing the CAR response of burned-out teachers, Pruessner et al. found that both stress and burnout had independent effects on cortisol secretion (positive for stress and negative for burnout), and they suggest that the HPA axis might be independently affected by stress and burnout [30]. Fries et al. hypothesize that the hypocortisolism seen in stress-related disorders is a protective mechanism which has evolved to conserve energy during threats that are beyond the organism's ability to cope [15].

Research in rats suggests that certain dopaminergic systems in the brain are involved in assessing the benefits versus energy demands of performing a task, with behaviour only proceeding if the benefit to the organism outweighs the energy expenditure. The brain regions involved include the nucleus accumbens, orbitofrontal cortex, amygdala, insular cortex, and anterior cingulate cortex (ACC). Boksem et al. propose that this unconscious "cost-benefit analysis" is central to mental fatigue, and that these dopaminergic systems may be fundamental to disorders such as burnout and CFS [31].

\section{Central fatigue}

Research on animals and athletes has shown that fatigue is predominantly an emotion that is generated by the brain in order to protect the body from potential exercise-induced damage. The brain integrates a number of physiological and psychological parameters - such as rate of heat accumulation, cerebral oxygenation, thirst, muscle soreness, blood lactose, emotional state, sleep deprivation, visual feedback, knowledge of the endpoint, degree of motivation, and other factors - to determine when to produce the experience of fatigue.

fMRI studies show that the brain regions involved in central fatigue include the insular cortex and the ACC. These brain regions are known to be involved in error detection, conflict detection, pain processing, reward-based learning, emotional regulation, and in creating emotional memories. The ACC has direct links to the motor cortex, which is thought to be the mechanism by which the brain makes movement extremely difficult during extreme fatigue. 
Studies show increased activation of the insular cortex during fatiguing exercise, as well as increased communication between the insular cortex and the motor cortex. Trained athletes show attenuated responses in the right insular cortex compared to non-athletes, suggesting that athletes have learned to attenuate their fatigue response to exercise. Noakes gives the term "Central Governor" to this fatigue-generating system in the brain [32]. These brain regions have also been shown to have abnormal activation in CFS [33].

\section{Persistent Burnout Theory of Chronic Fatigue Syndrome}

Burnout and CFS share similar symptoms and physiological abnormalities, as well as both being triggered by stress [34]. The main difference between burnout and CFS appears to be illness attribution: psychological for burnout and physical for CFS [34] [35]. Both CFS and burnout are associated with a hypofunction of the HPA axis, which appears to resolve in burnout after taking time off work, but persists in CFS.

The persistent burnout theory of CFS proposes that CFS is a state of persistent burnout, which remains after the initial stressors have been removed. The burnout is caused either by the cessation of long-term chronic stress, or begins during the period of stress, both of which are associated with hypocortisolism.

The key components of the theory are shown in Figure 1. A trigger-such as a virus or psychological stressor-results in the initial symptoms, and HPA axis hypofunction. Persistence is maintained either via changes in the HPA axis resulting in a dysregulation in the stress system [20], or due to cognitive behavioral factors [3], or a combination of both, with the illness being perpetuated by negative feedback mechanisms.

Burnout and HPA axis hypoactivation may be a protective mechanism that has evolved to protect the organism from the effects of chronic stress, and CFS may be a maladaptive burnout state that does not resolve after cessation of the stressor.

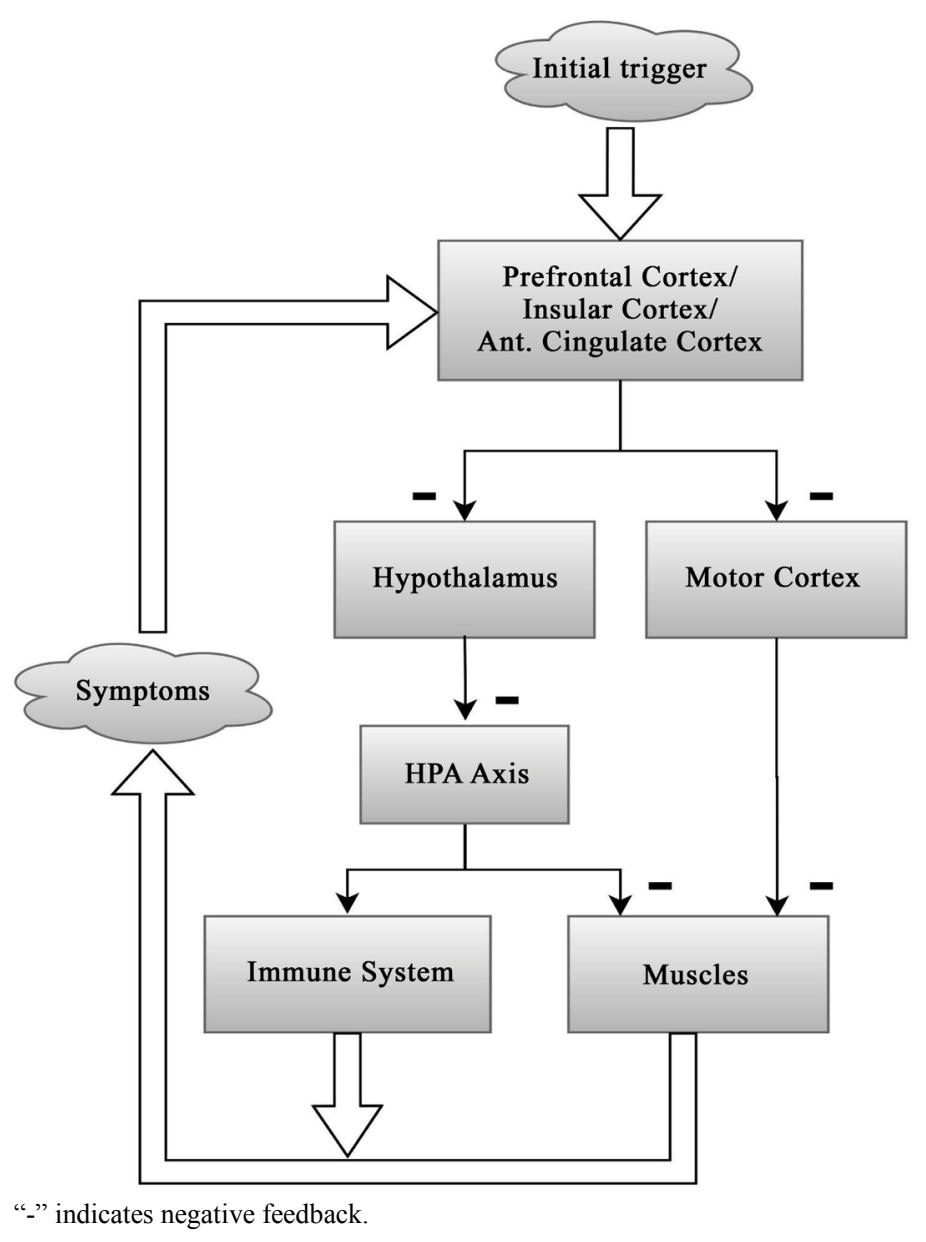

Figure 1. Proposed model of persistent burnout in CFS. 
Further research is needed to elucidate the brain structures responsible for burnout and CFS, but the prefrontal cortex (PFC) may be involved. The PFC is thought to be involved in long-term goal planning [36], and is an important part of the negative feedback regulation of the HPA axis [37]. A number of studies have shown that CFS patients have reduced grey matter volume in the lateral PFC, and one study has shown that this reduction is reversed after treatment with CBT [38].

A study on mice has shown that glucocorticoid receptors in the forebrain (which includes the prefrontal cortex, hippocampus, and basolateral amygdala) regulate the stress response to psychogenic stressors, reducing the HPA axis response through negative feedback. This negative feedback only seems to apply to psychogenic stressors, not physiological stressors [39].

The insular cortex and ACC may also be involved in CFS, given their importance in generating the sensations of mental [31] and physical [32] fatigue as described earlier. The ACC and insular cortex are implicated in both the "cost-benefit analysis" model of mental fatigue described by Boksem, and the "central governor" model of exercise fatigue described by Noakes, and have been shown to have abnormal activation in CFS. Their direct communication with the motor cortex, and their role in producing the emotional response to pain, could also explain the fatigue and pain seen in CFS.

\section{Recovery}

Recovery from CFS is difficult, and current treatments such as CBT and graded exercise therapy (GET) are only moderately effective for treating CFS. The fact that cognitive elements do not appear to make a therapy more effective, and that recovery is not associated with an increase in activity, calls into question the theories behind these treatments. Exercise may in fact be detrimental if it perceived as stressful by the patient. The moderate effectiveness of these (and other) treatments may simply be due to the fact that they give the HPA axis a benign "kick", reversing the state of persistent hypoactivation. Or perhaps they are simply a placebo that gives the patient self-efficacy and a positive goal to work towards.

Simply reducing stress and pacing activities does not generally result in recovery from CFS [40]. Anecdotally, patients seem to use a variety of unproven treatments that sometimes lead to recovery. The only common factors among all these treatments seem to be self-efficacy and the achievement of positive goals. Low self-efficacy has been shown to be a risk factor for both burnout and CFS [41] [42], and a lack of positive goals has been shown to be a factor in both persistent pain and workplace burnout [43]. Increasing self-efficacy has been shown to reduce fatigue, pain and depression [43].

The factors that appear to result in recovery from CFS correspond closely with the psychological concept of flow. Studies have shown that frequent flow experiences result in reduced burnout at work, and that work-related flow-absorption and enjoyment in particular-are associated with increased energy and reduced exhaustion/burnout after work [44] [45].

In summary, both burnout and CFS appear to be the result of long-term stress combined with a negative perception of the stress. With CFS, the illness itself may lead to continued stress and negative outlook, due to negative feedback, even in the absence of ongoing external stressors. Increasing positive goals, self-efficacy and flow experiences are thus a plausible treatment approach.

\section{Future Directions}

There are still a lot of unknowns about the etiology of CFS. There is some disagreement about the nature of the HPA axis dysfunction between studies, and it is unclear whether the HPA axis has a primary role in CFS. Future measurement of HPA axis and autonomic nervous system parameters in the days before and after exercise challenges may help to elucidate the nature of the HPA axis and autonomic dysfunction in patients, as well as shedding light on the nature of the post-exertional malaise seen in CFS. More effective treatments are desperately needed, and a better understanding of the etiology of the illness will likely lead to this happening.

\section{Proposed Treatment}

A possible novel treatment approach would be a therapy designed to enhance patient self-efficacy, positive goals and flow experiences. In addition, monitoring of both morning and evening cortisol during therapy would provide feedback to the patient. Such a therapy would: 
- Help the patient understand the possible triggers and perpetuating factors of their illness.

- Teach the patient about the mechanisms through which the HPA axis has influence over the immune system, digestive system and autonomic nervous system, how it is influenced by stress and burnout, and how it may cause symptoms.

- Teach the patient about the "central governor", and how the fatigue and pain are linked to emotions and psychological factors in brain regions such as the insular cortex and ACC.

- Collaborate with the patient in helping them to identify possible stressors or behaviors (such as being "action-prone") that may have triggered or perpetuated their illness, and resolving those stresses if necessary. Techniques such as mindfulness meditation or acceptance and commitment therapy may be useful in dealing with ongoing negative emotional stressors.

- Collaborate with the patient in helping them to understand the importance of factors such as self-efficacy, positive goals and flow experiences in the recovery process, and that simply reducing stresses is not always sufficient for recovery. Identify positive goals that the patient can work towards in their own life.

- Advise the patient on strategies for managing symptoms such as pain, insomnia, and dys-regulated sleep cycle.

- Take objective measurements at regular intervals, such as daily cortisol profile, and provide feedback to the patient.

\section{References}

[1] Fukuda, K., Straus, S.E., Hickie, I., Sharpe, M.C., Dobbins, J.G. and Komaroff, A. (1994) The Chronic Fatigue Syndrome: A Comprehensive Approach to Its Definition and Study. Annals of Internal Medicine, 121, 953-959. http://dx.doi.org/10.7326/0003-4819-121-12-199412150-00009

[2] Afari, N. and Buchwald, D. (2003) Chronic Fatigue Syndrome: A Review. American Journal of Psychiatry, 160, 221236. http://dx.doi.org/10.1176/appi.ajp.160.2.221

[3] Deary, V., Chalder, T. and Sharpe, M. (2007) The Cognitive Behavioural Model of Medically Unexplained Symptoms: A Theoretical and Empirical Review. Clinical Psychology Review, 27, 781-797. http://dx.doi.org/10.1016/j.cpr.2007.07.002

[4] Bansal, A.S., Bradley, A.S., Bishop, K.N., Kiani-Alikhan, S. and Ford, B. (2012) Chronic Fatigue Syndrome, the Immune System and Viral Infection. Brain, Behavior, and Immunity, 26, 24-31. http://dx.doi.org/10.1016/j.bbi.2011.06.016

[5] Van Houdenhove, B., Luyten, P. and Kempke, S. (2013) Chronic Fatigue Syndrome/Fibromyalgia: A "Stress-Adaptation" Model. Fatigue: Biomedicine, Health \& Behavior, 1, 137-147. http://dx.doi.org/10.1080/21641846.2013.795085

[6] Malouff, J.M., Thorsteinsson, E.B., Rooke, S.E., Bhullar, N. and Schutte, N.S. (2008) Efficacy of Cognitive Behavioral Therapy for Chronic Fatigue Syndrome: A Meta-Analysis. Clinical Psychology Review, 28, 736-745. http://dx.doi.org/10.1016/j.cpr.2007.10.004

[7] Vermeulen, R.C.W., Kurk, R.M., Visser, F.C., Sluiter, W. and Scholte, H.R. (2010) Patients with Chronic Fatigue Syndrome Performed Worse than Controls in a Controlled Repeated Exercise Study despite a Normal Oxidative Phosphorylation Capacity. Journal of Translational Medicine, 8, 93. http://dx.doi.org/10.1186/1479-5876-8-93

[8] Keller, B.A., Pryor, L.P. and Giloteaux, L. (2014) Inability of Myalgic Encephalomyelitis/Chronic Fatigue Syndrome Patients to Reproduce $\mathrm{VO}_{2}$ Peak Indicates Functional Impairment. Journal of Translational Medicine, $12,104$. http://dx.doi.org/10.1186/1479-5876-12-104

[9] Wiborg, J.F., Knoop, H., Stulemeijer, M., Prins, J.B. and Bleijenberg, G. (2010) How Does Cognitive Behaviour Therapy Reduce Fatigue in Patients with Chronic Fatigue Syndrome? The Role of Physical Activity. Psychological Medicine, 40, 1281. http://dx.doi.org/10.1017/S0033291709992212

[10] Friedberg, F. (2002) Does Graded Activity Increase Activity? A Case Study of Chronic Fatigue Syndrome. Journal of Behavior Therapy and Experimental Psychiatry, 33, 203-215. http://dx.doi.org/10.1016/S0005-7916(02)00038-1

[11] Hawkes, N. (2011) Dangers of Research into Chronic Fatigue Syndrome. BMJ, 342, d3780. http://dx.doi.org/10.1136/bmj.d3780

[12] Natelson, B.H. and Lange, G. (2002) A Status Report on Chronic Fatigue Syndrome. Environmental Health Perspectives, 110, 673. http://dx.doi.org/10.1289/ehp.02110s4673

[13] Herbert, T.B. and Cohen, S. (1993) Stress and Immunity in Humans: A Meta-Analytic Review. Psychosomatic Medicine, 55, 364-379. http://dx.doi.org/10.1097/00006842-199307000-00004 
[14] Papadopoulos, A.S. and Cleare, A.J. (2012) Hypothalamic-Pituitary-Adrenal Axis Dysfunction in Chronic Fatigue Syndrome. Nature Reviews Endocrinology, 8, 22-32. http://dx.doi.org/10.1038/nrendo.2011.153

[15] Fries, E., Dettenborn, L. and Kirschbaum, C. (2009) The Cortisol Awakening Response (CAR): Facts and Future Directions. International Journal of Psychophysiology, 72, 67-73. http://dx.doi.org/10.1016/j.ijpsycho.2008.03.014

[16] Salit, I.E. (1997) Precipitating Factors for the Chronic Fatigue Syndrome. Journal of Psychiatric Research, $31,59-65$. http://dx.doi.org/10.1016/S0022-3956(96)00050-7

[17] Silverman, M.N., Pearce, B.D., Biron, C.A. and Miller, A.H. (2005) Immune Modulation of the Hypothalamic-Pituitary-Adrenal (HPA) Axis during Viral Infection. Viral Immunology, 18, 41-78. http://dx.doi.org/10.1089/vim.2005.18.41

[18] Rohleder, N., Wolf, J.M. and Kirschbaum, C. (2003) Glucocorticoid Sensitivity in Humans-Interindividual Differences and Acute Stress Effects. Stress: The International Journal on the Biology of Stress, 6, 207-222. http://dx.doi.org/10.1080/1025389031000153658

[19] Van Houdenhove, B., Neerinckx, E., Onghena, P., Lysens, R. and Vertommen, H. (2001) Premorbid "Overactive" Lifestyle in Chronic Fatigue Syndrome and Fibromyalgia: An Etiological Factor or Proof of Good Citizenship? Journal of Psychosomatic Research, 51, 571-576. http://dx.doi.org/10.1016/S0022-3999(01)00247-1

[20] Van Houdenhove, B., Eede, F.V.D. and Luyten, P. (2009) Does Hypothalamic-Pituitary-Adrenal Axis Hypofunction in Chronic Fatigue Syndrome Reflect a Crash in the Stress System? Medical Hypotheses, 72, 701-705. http://dx.doi.org/10.1016/j.mehy.2008.11.044

[21] Gaab, J., Hüster, D., Peisen, R., Engert, V., Schad, T., Schürmey, T.H. and Ehlert, U. (2002) Low-Dose Dexamethasone Suppression Test in Chronic Fatigue Syndrome and Health. Psychosomatic Medicine, 64, 311-318. http://dx.doi.org/10.1097/00006842-200203000-00015

[22] Miller, G.E., Chen, E. and Zhou, E.S. (2007) If It Goes Up, Must It Come Down? Chronic Stress and the Hypothalamic-Pituitary-Adrenocortical Axis in Humans. Psychological Bulletin, 133, 25-45. http://dx.doi.org/10.1037/0033-2909.133.1.25

[23] Charmandari, E., Tsigos, C. and Chrousos, G. (2005) Endocrinology of the Stress Response. Annual Review of Physiology, 67, 259-284. http://dx.doi.org/10.1146/annurev.physiol.67.040403.120816

[24] Fries, E., Hesse, J., Hellhammer, J. and Hellhammer, D.H. (2005) A New View on Hypocortisolism. Psychoneuroendocrinology, 30, 1010-1016. http://dx.doi.org/10.1016/j.psyneuen.2005.04.006

[25] Nijhof, S.L., Rutten, J.M., Uiterwaal, C.S., Bleijenberg, G., Kimpen, J.L. and Putte, E.M. (2014) The Role of Hypocortisolism in Chronic Fatigue Syndrome. Psychoneuroendocrinology, 42, 199-206. http://dx.doi.org/10.1016/j.psyneuen.2014.01.017

[26] Roberts, A.D., Papadopoulos, A.S., Wessely, S., Chalder, T. and Cleare, A.J. (2009) Salivary Cortisol Output before and after Cognitive Behavioural Therapy for Chronic Fatigue Syndrome. Journal of Affective Disorders, 115, $280-286$. http://dx.doi.org/10.1016/j.jad.2008.09.013

[27] Hall, D.L., Lattie, E.G., Antoni, M.H., Fletcher, M.A., Czaja, S., Perdomo, D. and Klimas, N.G. (2014) Stress Management Skills, Cortisol Awakening Response, and Post-Exertional Malaise in Chronic Fatigue Syndrome. Psychoneuroendocrinology, 49, 26-31. http://dx.doi.org/10.1016/j.psyneuen.2014.06.021

[28] Demerouti, E., Bakker, A.B., Nachreiner, F. and Schaufeli, W.B. (2001) The Job Demands-Resources Model of Burnout. Journal of Applied Psychology, 86, 499-512. http://dx.doi.org/10.1037/0021-9010.86.3.499

[29] Chida, Y. and Steptoe, A. (2009) Cortisol Awakening Response and Psychosocial Factors: A Systematic Review and Meta-Analysis. Biological Psychology, 80, 265-278. http://dx.doi.org/10.1016/j.biopsycho.2008.10.004

[30] Pruessner, J.C., Hellhammer, D.H. and Kirschbaum, C. (1999) Burnout, Perceived Stress, and Cortisol Responses to Awakening. Psychosomatic Medicine, 61, 197-204. http://dx.doi.org/10.1097/00006842-199903000-00012

[31] Boksem, M.A. and Tops, M. (2008) Mental Fatigue: Costs and Benefits. Brain Research Reviews, 59, 125-139. http://dx.doi.org/10.1016/j.brainresrev.2008.07.001

[32] Noakes, T.D. (2012) Fatigue Is a Brain-Derived Emotion That Regulates the Exercise Behavior to Ensure the Protection of Whole Body Homeostasis. Frontiers in Physiology, 3, 1-13. http://dx.doi.org/10.3389/fphys.2012.00082

[33] De Lange, F.P., Kalkman, J.S., Bleijenberg, G., Hagoort, P., vd Werf, S.P., Van der Meer, J.W. and Toni, I. (2004) Neural Correlates of the Chronic Fatigue Syndrome-An fMRI Study. Brain, 127, 1948-1957. http://dx.doi.org/10.1093/brain/awh225

[34] Leone, S.S., Wessely, S., Huibers, M.J., Knottnerus, J.A. and Kant, I. (2011) Two Sides of the Same Coin? On the History and Phenomenology of Chronic Fatigue and Burnout. Psychology and Health, 26, 449-464. http://dx.doi.org/10.1080/08870440903494191

[35] Huibers, M.J.H., Beurskens, A.J.H.M., Prins, J.B., Kant, I.J., Bazelmans, E., Van Schayck, C.P., Bleijenberg, G., et al. 
(2003) Fatigue, Burnout, and Chronic Fatigue Syndrome among Employees on Sick Leave: Do Attributions Make the Difference? Occupational and Environmental Medicine, 60, i26-i31. http://dx.doi.org/10.1136/oem.60.suppl 1.i26

[36] Miller, E.K. and Cohen, J.D. (2001) An Integrative Theory of Prefrontal Cortex Function. Annual Review of Neuroscience, 24, 167-202. http://dx.doi.org/10.1146/annurev.neuro.24.1.167

[37] Herman, J.P. and Cullinan, W.E. (1997) Neurocircuitry of Stress: Central Control of the Hypothalamo-PituitaryAdrenocortical Axis. Trends in Neurosciences, 20, 78-84. http://dx.doi.org/10.1016/S0166-2236(96)10069-2

[38] de Lange, F.P., Koers, A., Kalkman, J.S., Bleijenberg, G., Hagoort, P., van Der Meer, J.W. and Toni, I. (2008) Increase in Prefrontal Cortical Volume Following Cognitive Behavioural Therapy in Patients with Chronic Fatigue Syndrome. Brain, 131, 2172-2180. http://dx.doi.org/10.1093/brain/awn140

[39] Furay, A.R., Bruestle, A.E. and Herman, J.P. (2008) The Role of the Forebrain Glucocorticoid Receptor in Acute and Chronic Stress. Endocrinology, 149, 5482-5490. http://dx.doi.org/10.1210/en.2008-0642

[40] White, P.D., Goldsmith, K.A., Johnson, A.L., Potts, L., Walwyn, R., DeCesare, J.C., Sharpe, M., et al. (2011) Comparison of Adaptive Pacing Therapy, Cognitive Behaviour Therapy, Graded Exercise Therapy, and Specialist Medical Care for Chronic Fatigue Syndrome (PACE): A Randomised Trial. The Lancet, 377, 823-836. http://dx.doi.org/10.1016/S0140-6736(11)60096-2

[41] Schwarzer, R. and Hallum, S. (2008) Perceived Teacher Self-Efficacy as a Predictor of Job Stress and Burnout: Mediation Analyses. Applied Psychology, 57, 152-171. http://dx.doi.org/10.1111/j.1464-0597.2008.00359.x

[42] Findley, J.C., Kerns, R., Weinberg, L.D. and Rosenberg, R. (1998) Self-Efficacy as a Psychological Moderator of Chronic Fatigue Syndrome. Journal of Behavioral Medicine, 21, 351-362. http://dx.doi.org/10.1023/A:1018726713470

[43] Maes, S. and Karoly, P. (2005) Self-Regulation Assessment and Intervention in Physical Health and Illness: A Review. Applied Psychology, 54, 267-299. http://dx.doi.org/10.1111/j.1464-0597.2005.00210.x

[44] Lavigne, G.L., Forest, J. and Crevier-Braud, L. (2012) Passion at Work and Burnout: A Two-Study Test of the Mediating Role of Flow Experiences. European Journal of Work and Organizational Psychology, 21, 518-546. http://dx.doi.org/10.1080/1359432X.2011.578390

[45] Demerouti, E., Bakker, A.B., Sonnentag, S. and Fullagar, C.J. (2012) Work-Related Flow and Energy at Work and at Home: A Study on the Role of Daily Recovery. Journal of Organizational Behavior, 33, 276-295. http://dx.doi.org/10.1002/job.760

\section{Abbreviations}

ACC: Anterior cingulate cortex

CAR: Cortisol awakening response

CBT: Cognitive behavioural therapy

CFS: Chronic fatigue syndrome

EBV: Epstein-Barr virus

fMRI: Functional magnetic resonance imaging

GAS: General adaptation syndrome

GET: Graded exercise therapy

HHV6: Human herpesvirus 6

HPA axis: Hypothalamic-pituitary-adrenal axis

PEM: Post-exertional malaise

PFC: Prefrontal cortex

PTSD: Post-traumatic stress disorder 